\title{
Metformin-induced apoptosis facilitates degradation of the cellular caspase 8 (FLICE)-like inhibitory protein through a caspase-dependent pathway in human renal cell carcinoma A498 cells
}

\author{
JI-HOON JANG, IN-HWAN SONG, EON-GI SUNG, TAE-JIN LEE and JOO-YOUNG KIM
}

Department of Anatomy, College of Medicine, Yeungnam University, Daegu 42415, Republic of Korea

Received February 12, 2018; Accepted May 4, 2018

DOI: $10.3892 / \mathrm{ol} .2018 .8832$

\begin{abstract}
Renal cell carcinoma (RCC) is one of the most common types of cancer in adults. Previous studies have reported that the survival rate was significantly lower for renal cancer patients with diabetes than for those without diabetes. Metformin is a well-known anti-diabetic agent used for the treatment of type 2 diabetes mellitus (T2DM). It also inhibits cell proliferation and angiogenesis and is known to possess antitumor effects. However, the molecular mechanism for metformin-induced apoptosis in renal cell carcinoma is not understood. In the present study, treatment with metformin induced apoptosis in A498 cells in a dose-dependent manner. It was revealed that degradation of cellular caspase 8 (FLICE)-like inhibitory protein (c-FLIP) and activation of procaspase- 8 were associated with metformin-mediated apoptosis. By contrast, treatment with metformin did not affect the mRNA level of c-FLIP ${ }_{\mathrm{L}}$ in A498 cells. Treatment with benzyloxycarbonyl-Val-Ala-Asp-fluoromethyl ketone (z-VAD-fmk, a pan-caspase inhibitor) almost completely blocked metformin-induced apoptosis and degradation of c-FLIP $_{\mathrm{L}}$ protein. However, N-acetyl-L-cysteine (NAC), a reactive oxygen species (ROS) scavenger, did not inhibit metformin-mediated apoptosis in A498 cells. Taken together, the results of the present study demonstrated that metformin-induced apoptosis involved degradation of the c-FLIP L $_{\text {L }}$ potein and activation of caspase- 8 in human renal cell carcinoma A498 cells and suggested that metformin could be potentially used for the treatment of renal cancer.
\end{abstract}

Correspondence to: Dr Joo-Young Kim or Dr Tae-Jin Lee, Department of Anatomy, College of Medicine, Yeungnam University, 170 Hyeonchung-Ro, Nam-Gu, Daegu 42415, Republic of Korea

E-mail: jookim@med.yu.ac.kr

E-mail: tjlee@med.yu.ac.kr

Key words: metformin, A498, apoptosis, caspase, cellular caspase 8 (FLICE)-like inhibitory protein

\section{Introduction}

Renal cell carcinoma (RCC), a neoplastic lesion of the kidney in humans, accounts for $\sim 90 \%$ of kidney tumors (1). It is difficult to treat with conventional treatments including chemical, hormone and radiation therapy, and cannot be treated without surgery $(2,3)$. A previous report described metformin may improve the incidence of cancer-associated diabetes (4). Thus far, RCC has been treated chemically and immunologically. However, there is an urgent requirement to identify more efficient chemo-preventive agents for treating RCC.

Metformin is the most widely used biguanide drug for treating type 2 diabetes mellitus patients (5). It has been reported that metformin has anti-diabetic and anticancer effects on colorectal and pancreatic cancer cells (6,7). It has also been revealed to exert anti-neoplastic effects in epithelial ovarian cancer (8). Furthermore, metformin has been demonstrated to reduce the risk of cancer prevalence in diabetic patients $(9,10)$. Metformin demonstrated a marked anticancer effect in various cells of different types of human cancer, including breast cancer, renal cancer, glioblastoma, insulinoma and cholangiocarcinoma via cell growth inhibition, cell cycle arrest, apoptosis, adenosine monophosphate-activated protein kinase (AMPK) signaling and tumor growth inhibition (11-15). Although the effect of metformin on A498 cells has been reported (12), the apoptosis-mediated molecular mechanism of action of metformin remains unclear in human renal cell carcinoma A498 cells.

The cellular caspase 8 (FLICE)-like inhibitory protein (c-FLIP) gene makes three isoforms, namely c-FLIP ${ }_{\mathrm{L}}, \mathrm{c}-\mathrm{FLIP}_{\mathrm{S}}$ and c-FLIP ${ }_{R}$, via alternative splicing in humans. These proteins are well known as anti-apoptotic proteins; each exert this effect via different mechanisms (16). In previous reports, c-FLIP was demonstrated to be an independent negative prognostic factor in ovarian, endometrial and colon cancer cells (17-19). c-FLIP $_{\mathrm{L}}$ is known to be involved in the inhibition of caspase- 8 activation-mediated apoptosis $(18,20)$. The activation of caspase-8 leads to death-inducing signaling complex (DISC) and augmented apoptosis via caspase-3 activation. Previous studies have demonstrated that treatment with metformin suppressed the c-FLIP $\mathrm{L}_{\mathrm{L}}$ protein expression level in human lung adenocarcinoma and bladder cancer $(21,22)$. 
In the present study, the mechanism of metforminmediated apoptosis in human renal cell carcinoma A498 cells was investigated. It was revealed that degradation of $\mathrm{c}-\mathrm{FLIP}_{\mathrm{L}}$ protein and activation of caspase- 8 were associated with metformin-induced apoptosis.

\section{Materials and methods}

Cell culture. A498 human renal carcinoma cells were procured from the American Type Culture Collection (ATCC; Manassas, VA, USA). Dulbecco's modified Eagle's medium (DMEM; catalog no. LM 001-05; Welgene, Inc., Kyungsan, Korea) containing $10 \%$ fetal bovine serum (FBS; catalog no. S001-07; Welgene, Inc.), 20 mM 4-(2-hydroxyethyl)-1-piperazineethanesulfonic acid (HEPES; catalog no. H0887; Sigma-Aldrich; Merck KGaA, Darmstadt, Germany) buffer and $100 \mu \mathrm{g} / \mathrm{ml}$ gentamicin (catalog no. 15710-072; Invitrogen; Thermo Fisher Scientific, Inc., Waltham, MA, USA) was used as the culture medium. The cells were cultured in an incubator at $37^{\circ} \mathrm{C}$ with humidified $5 \% \mathrm{CO}_{2}$.

Cell morphology. A498 human renal carcinoma cells were treated with an inhibitor in either the absence or presence of metformin $(10 \mathrm{mM})$. Following $24 \mathrm{~h}$ incubation, morphological changes were visualized with light microscopy (catalog no. DFC495; Leica Microsystems GmbH, Wetzlar, Germany) at x200 magnification. The images were analyzed using the i-Solution program (IMT i-Solution, Burnaby, BC, Canada).

Flow cytometry analysis. Cell counting was performed using a hemocytometer. Metformin was immediately added to cell cultures at the indicated concentrations. Approximately $0.4 \times 10^{6}$ cells were resuspended in $100 \mu \mathrm{l}$ PBS (catalog no. 17-517Q; Lonza, Walkersville, MD, USA), and $200 \mu \mathrm{l}$ of $95 \%$ ethanol (catalog no. 1.00983.1011; Merck $\mathrm{KGaA}$ ) was added during vortexing. The cells were incubated at $4^{\circ} \mathrm{C}$ for $1 \mathrm{~h}$, washed in PBS, and resuspended in $250 \mu \mathrm{l}$ $1.12 \%$ sodium citrate buffer ( $\mathrm{pH} 8.4$ ) along with $12.5 \mu 1$ RNase. Incubation was continued for $30 \mathrm{~min}$ at $37^{\circ} \mathrm{C}$. Cellular DNA was stained with $250 \mu \mathrm{l}$ (1:1 dilution) propidium iodide (50 $\mu \mathrm{g} / \mathrm{ml}$; catalog no. p4170; Sigma-Aldrich; Merck KGaA) for $30 \mathrm{~min}$ at $37^{\circ} \mathrm{C}$, and the relative DNA contents of the stained cells were analyzed using fluorescence-activated cell sorting (FACS) on the BD FACS Cato II flow cytometer (BD Biosciences, San Jose, CA, USA).

Western blot analysis. A498 whole-cell lysates were prepared by resuspending $0.4 \times 10^{6}$ cells in $50 \mu 1$ lysis buffer $(137 \mathrm{mM}$ $\mathrm{NaCl}, 15 \mathrm{mM}$ EGTA, $0.1 \mathrm{mM}$ sodium orthovanadate, $15 \mathrm{mM}$ $\mathrm{MgCl}_{2}, 0.1 \%$ Triton X-100, $25 \mathrm{mM}$ MOPS, $100 \mu \mathrm{M}$ phenylmethylsulfonyl fluoride and $20 \mu \mathrm{M}$ leupeptin, adjusted to $\mathrm{pH}$ 7.2). The cells were disrupted by sonication and protein extracted at $4^{\circ} \mathrm{C}$ for $30 \mathrm{~min}$. Protein concentrations were quantified using the BCA assay kit (catalog no. 23225; Thermo Fisher Scientific, Inc.), according to the manufacturer's protocol. The proteins $(50 \mu \mathrm{g})$ were separated using $10 \%$ SDS-PAGE gel and electrotransferred onto nitrocellulose membranes (catalog no. 23225; GE Healthcare, Chicago, IL, USA). The membrane was blocked with $5 \%$ skim milk in
Tris-buffered saline (TBS) for $30 \mathrm{~min}$ at room temperature. The anti c-FLIP ${ }_{\mathrm{L}}$ (dilution, 1:700; catalog no. ALX-804-961) antibody was obtained from Enzo Life Sciences, Inc. (Farmingdale, NY, USA). The anti-PARP (dilution, 1:1,000; catalog no. 9542) antibody was purchased from Cell Signaling Technology, Inc. (Danvers, MA, USA). The anti-B-cell lymphoma-2 (Bcl-2); (dilution, 1:700; catalog no. sc-783), anti-B-cell lymphoma-extra-large (Bcl-xL); (dilution, 1:1,000; catalog no. sc-634), anti-myeloid cell leukemia-1 (Mcl-1); (dilution, 1:1,000; catalog no. sc-819), anti-cellular inhibitor of apoptosis 2 (cIAP-2); (dilution, 1:1,000; catalog no. sc-7944) and anti-actin (dilution, 1:2,000; catalog no. sc-1616) antibodies were procured from Santa Cruz Biotechnology Inc. (Dallas, TX, USA). The anti-XIAP (dilution, 1:5,000; catalog no. 610762) antibody was supplied by BD Biosciences (San Jose, CA, USA). Membranes were incubated with the primary antibodies overnight at $4^{\circ} \mathrm{C}$. Following six washes with TBS (each for $5 \mathrm{~min}$ ), the membranes were incubated with the indicated secondary antibody for $1 \mathrm{~h}$ at room temperature and washed six times with TBS. The secondary goat anti-rabbit immunoglobulin $\mathrm{G}$ ( $\mathrm{Ig} \mathrm{G})$-horseradish peroxidase (HRP) conjugated (dilution 1:1,000; catalog no. sc-2004) and goat anti-mouse IgG-HRP (dilution 1:1,000; catalog no. sc-2005) antibodies were procured from Santa Cruz Biotechnology, Inc. Specific proteins were detected using an ECL western blotting kit (catalog no. WBKLS0500; Merck KGaA). Proteins were detected using by ImageQuant LAS 4000 Mini Imaging System (GE Healthcare).

Transfection. A498 cells were seeded onto 6-well plates at a concentration of $0.2 \times 10^{6}$ cells/well and incubated overnight at $37^{\circ} \mathrm{C}$. The pcDNA 3.1 vector and pcDNA $3.1 \mathrm{c}-\mathrm{FLIP}_{\mathrm{L}}$ plasmid were provided by Professor Tae-Jin Lee (Yeungnam University, South Korea). They were then transfected with control plasmid pcDNA 3.1 vector or pcDNA 3.1-c-FLIP L $_{\text {plasmid }}$ for $5 \mathrm{~h}$ using lipofectamine 2000 (catalog no. 11668-019; Invitrogen; Thermo Fisher Scientific, Inc.) in Opti-MEM medium (catalog no. 31985-070; Invitrogen; Thermo Fisher Scientific, Inc.). Following transfection, the cells were cultured in DMEM supplemented with $10 \%$ FBS for $12 \mathrm{~h}$. Next, the cells were treated with metformin for $24 \mathrm{~h}$. Finally, the cells were analyzed for c-FLIP $\mathrm{L}_{\mathrm{L}}$ expression using western blotting.

RNA isolation and reverse transcription-polymerase chain reaction $(R T-P C R)$. c-FLIP $\mathrm{L}_{\mathrm{L}} \mathrm{mRN}$ expression was determined by RT-PCR. Total RNA was extracted from A498 cells using the EasyBlue reagent (catalog no. 17061; Thermo Fisher Scientific, Inc.). cDNA was prepared using M-MLV reverse transcriptase (catalog no. 18057018; Thermo Fisher Scientific, Inc.), according to the manufacturer's protocol. In addition, the total cellular RNA was reverse-transcribed using a random primer and subsequently amplified using PCR. PCR primers were purchased from GenoTech (Daejeon, Korea). GAPDH was used as the internal control. The PCR cycling conditions used were as follows: For c-FLIP ${ }_{\mathrm{L}}: 95^{\circ} \mathrm{C}$ for $45 \mathrm{sec}$, $54^{\circ} \mathrm{C}$ for $45 \mathrm{sec}, 72^{\circ} \mathrm{C}$ for $45 \mathrm{sec}(33 \mathrm{cycles})$ and for GAPDH: $94^{\circ} \mathrm{C}$ for $30 \mathrm{sec}, 58^{\circ} \mathrm{C}$ for $45 \mathrm{sec}, 72^{\circ} \mathrm{C}$ for $42 \mathrm{sec}(25$ cycles). The following primer sequences were used to amplify c-FLIP and GAPDH: For c-FLIP ${ }_{\mathrm{L}}$ : 5'-CGGACTATAGAGTGCTGA 

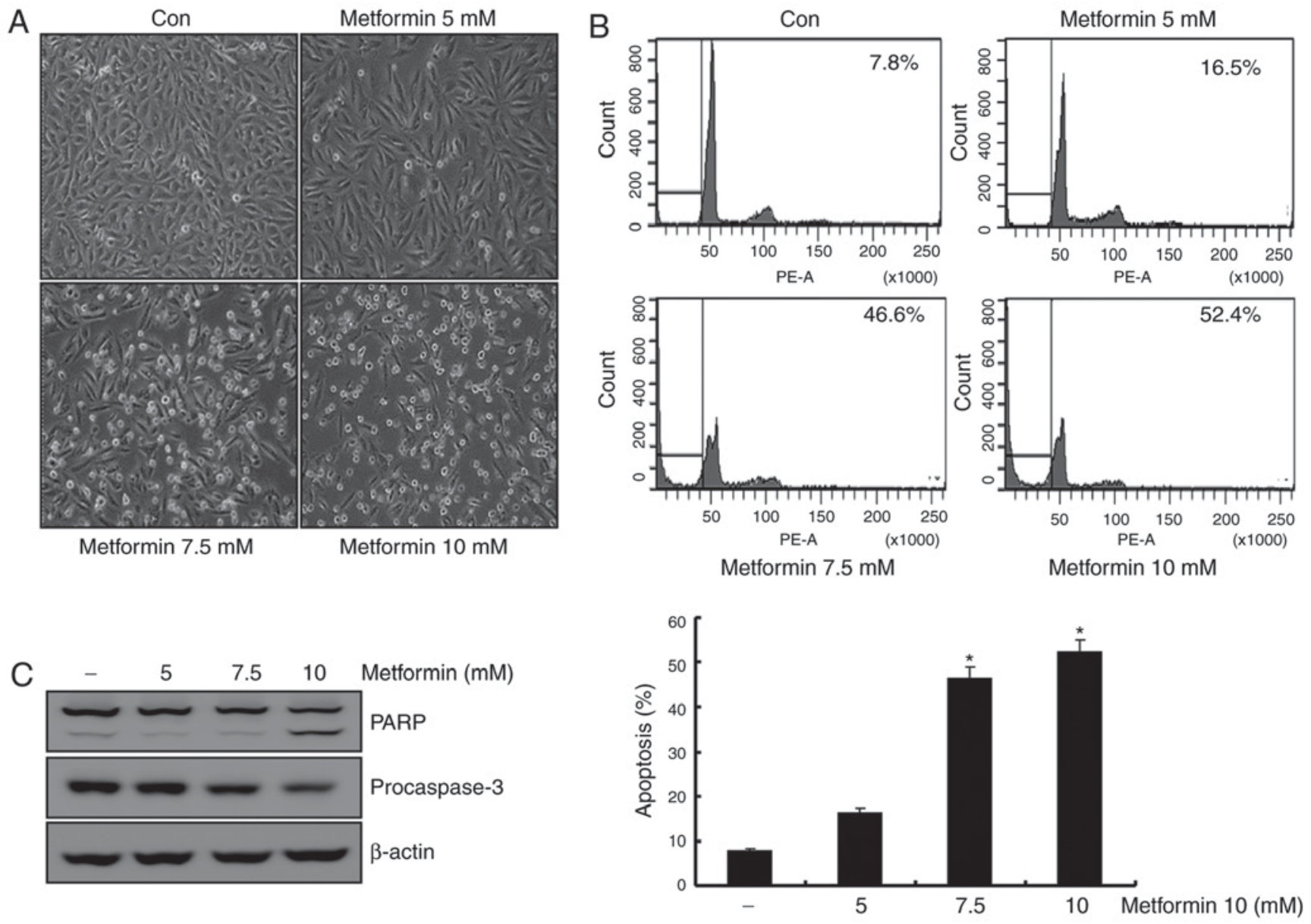

Figure 1. Metformin induces apoptosis in a dose-dependent manner in A498 cells. (A) A498 human renal carcinoma cells were treated with the indicated concentration of metformin. After $24 \mathrm{~h}$, morphological changes were observed using a microscope at x 200 magnification. (B) A498 cells were treated with metformin $(0,5,7.5$ and $10 \mathrm{mM})$ for $24 \mathrm{~h}$. Apoptosis was determined by flow cytometry. Representative FACS histograms are presented in the upper panel, cumulative data are presented in the lower panel. (C) A498 cells were treated with metformin for $24 \mathrm{~h}$, and PARP, procaspase-3 and $\beta$-actin expression was analyzed using western blotting. $\beta$-actin was used as the loading control. All data are expressed as the mean \pm standard deviation of three independent experiments. " $\mathrm{P}<0.05$ compared with untreated cells. FACS, Fluorescence-activated cell sorting; PARP, poly (ADP-ribose) polymerase.

TGG-3' (forward) and 5'-GATTATCAGGCAGATTCCTAG-3' (reverse); and for GAPDH: 5'-AGGTCGGAGTCAACGGAT TTG-3' (forward) and 5'-GTGATGGCATGGACTGTGGT-3' (reverse). PCR products were analyzed by electrophoresis using $1.5 \%$ agarose gels and visualized by ethidium bromide using UV light gel (catalog no. WGD30; DAIHAN Scientific, Seoul, Korea).

Measurement of reactive oxygen species. A498 cells were plated in 6 well plates at a density of $0.4 \times 10^{6}$ cells/well and incubated for $24 \mathrm{~h}$. The cells were incubated with metformin for $1 \mathrm{~h}$ and loaded with $10 \mu \mathrm{M}$ 2',7'-dichlorofluorescin diacetate $\left(\mathrm{H}_{2}\right.$ DCFDA; Sigma-Aldrich; Merck KGaA) for $30 \mathrm{~min}$ at $37^{\circ} \mathrm{C}$. Next, they were washed three times with PBS. Fluorescence was measured using flow cytometry. ROS generation was assessed by the dichlorofluorescence in fluorescence intensity (FL-1, $530 \mathrm{~nm}$ ) of 10,000 cells using the BD FACS Cato II flow cytometer (BD Biosciences).

Statistical analysis. Data were analyzed using one-way ANOVA followed by post hoc comparisons (Student-Newman-Keuls) using the Statistical Package for Social Sciences 8.0 (SPSS, Inc., Chicago, IL, USA). At least three independent experiments were performed. The data were expressed as the mean \pm standard deviation and $\mathrm{P}<0.05$ was considered to indicate a statistically significant difference.

\section{Results}

Metformin induces apoptosis in human renal cell carcinoma A498 cells. Previous studies reported that metformin induces apoptosis in renal cancer and breast cancer cell lines $(12,23)$. To determine the apoptotic effects of metformin on A498 cells, these cells were treated with various concentrations of metformin $(0,5,7.5$ and $10 \mathrm{mM})$ for $24 \mathrm{~h}$. In a dose-dependent manner, the metformin-stimulated A498 cells demonstrated features of apoptosis, including cell contraction and rounding and segregation of cells from the well (Fig. 1A). As presented in Fig. 1B, treatment of A498 cells with metformin resulted in a dose-dependent increase in sub-G1 populations. Additionally, treatment of A498 cells with metformin stimulated a reduction in the protein levels of the $32-\mathrm{kDa}$ precursor (procaspase-3), along with the concomitant cleavage of PARP, a protein substrate for caspases (Fig. 1C). These results suggested that metformin-treated A498 cells demonstrated an increase in the Sub-G1 population in a dose-dependent manner. 

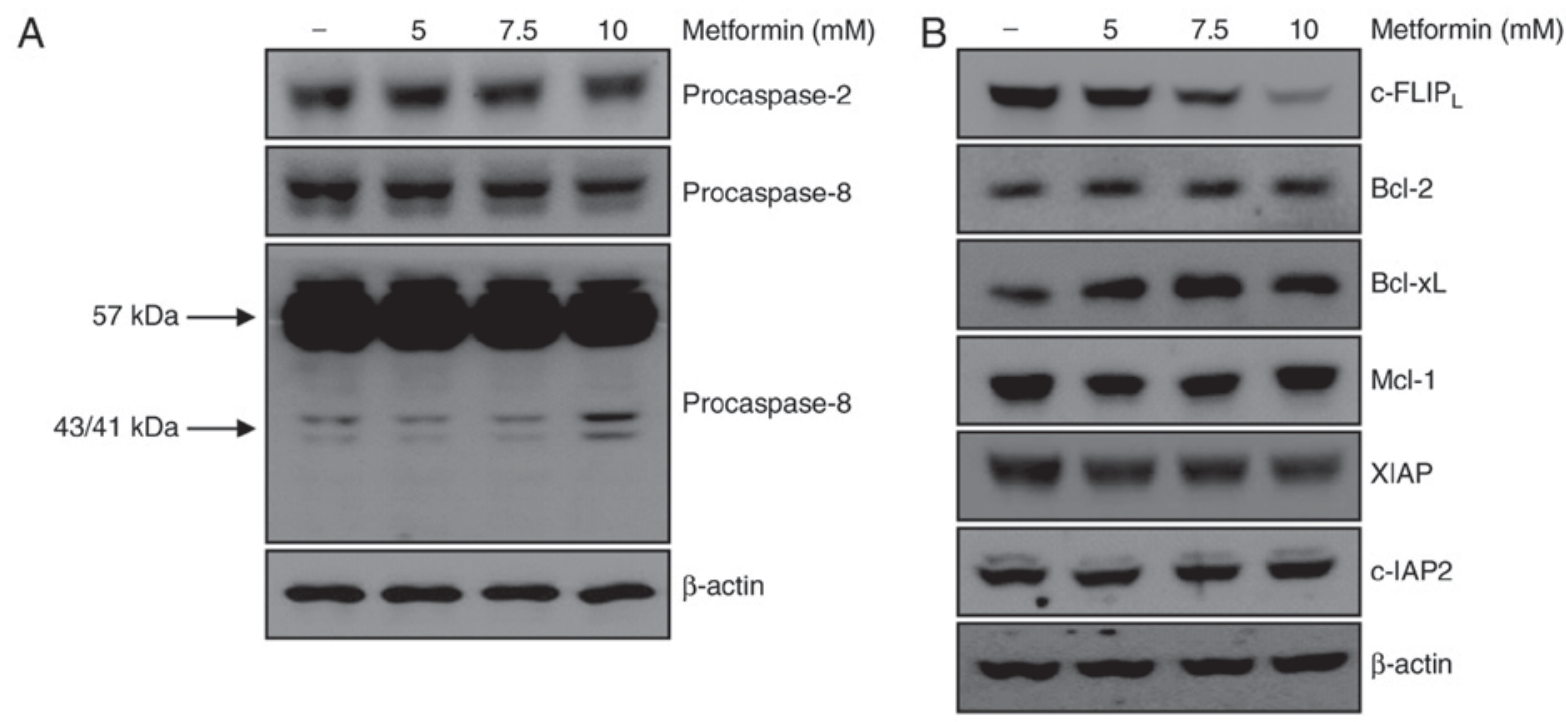

Figure 2. Metformin-induced apoptosis is associated with activation of procaspase- 8 and degradation of c-FLIP $\mathrm{L}_{\text {. }}(\mathrm{A}) \mathrm{A} 498 \mathrm{cells}$ were treated with metformin for $24 \mathrm{~h}$, and procaspase- 2 and procaspase- 8 expression was analyzed using western blotting. $\beta$-actin was used as the loading control. (B) A498 cells were treated with various concentrations of metformin for $24 \mathrm{~h}$. c-FLIP $\mathrm{L}_{\mathrm{L}}, \mathrm{Bcl}-2, \mathrm{Bcl}-\mathrm{xL}, \mathrm{Mcl}-1$, XIAP and c-IAP ${ }_{2}$ expression was determined using western blot analysis. $\beta$-actin served as the loading control. c-FLIP, cellular FLICE (FADD-like IL-1 $\beta$-converting enzyme)-inhibitory protein; Bcl-2, B-cell lymphoma 2; Bcl-xL, B-cell lymphoma-extra-large; Mcl-1, myeloid cell leukemia-1, XIAP, X-linked inhibitor of apoptosis protein; c-IAP, cellular inhibitor of apoptosis protein, baculoviral IAP repeat containing 3.

Metformin-induced apoptosis is modulated through degradation of the c-FLIP $P_{L}$ protein in A498 cells. Caspases are important regulators of apoptotic cell death associated with apoptotic signaling pathways in various cancer cells (24). The present study examined whether activation of the caspase signaling pathway served a key role in metformin-mediated apoptosis. Treatment of A498 cells with metformin did not affect the activation of caspase-2. However, treatment with metformin for $24 \mathrm{~h}$ resulted in the appearance of p43/41-kDa fragments of caspase-8 (Fig. 2A). These results demonstrated that caspase- 8 activation was involved in metformin-induced apoptosis in A498 cells. The association between metformin-induced apoptosis and regulation of other apoptotic modulators was investigated. As presented in Fig. 2B, protein expression levels of anti-apoptotic molecules including Bcl-2, Bcl-xL, Mcl-1, XIAP and c-IAP ${ }_{2}$ were not altered by metformin treatment. c-FLIP is a major regulator of the activity of caspase-8 (20). The protein level of c-FLIP decreased following metformin treatment in A498 cells in a dose-dependent manner. Taken together, degradation of the c-FLIP ${ }_{L}$ protein was involved in metformin-induced apoptosis via activation of caspase- 8 .

Metformin-mediated apoptosis is associated with activation of the caspase signaling pathway. The role of the caspase signaling pathway in metformin-mediated apoptosis was investigated. As presented in Fig. 3A, metformin-induced apoptosis was blocked following pretreatment with a general caspase inhibitor, z-VAD-fmk. Sub-G1 population was markedly decreased by treatment with z-VAD-fmk in the presence of metformin (Fig. 3B). In addition, treatment with z-VAD-fmk prevented the cleavage of PARP and caspase-3 activation (Fig. 3B). These data indicated that metformin-induced apoptosis was mediated by caspase-dependent apoptosis in the presence of z-VAD-fmk.
Metformin-mediated apoptosis is dependent on the degradation of $c$-FLIP $P_{L}$ protein in $A 498$ cells. The association between caspase- 8 activation and metformin-mediated apoptosis was investigated. Treatment with metformin led to c-FLIP $_{\mathrm{L}}$ degradation, which was recovered by z-VAD-fmk (Fig. 4A). To determine whether the mRNA level of c-FLIP $P_{L}$ was associated with protein level in A498 human renal cell carcinoma cells, the c-FLIP $\mathrm{L}_{\mathrm{L}}$ mRA level was examined using RT-RCR. As demonstrated in Fig. 4B, c-FLIP $\mathrm{L}_{\mathrm{L}}$ mRA level remained constant following metformin treatment in A498 cells at indicated concentrations. A previous study reported that c-FLIP functions as an anti-apoptotic regulator and is overexpressed in various cancer cell lines (25). To determine whether the reduced level of c-FLIP ${ }_{L}$ was involved in the induction of apoptosis in metformin-treated A498 cells, c-FLIP ${ }_{\mathrm{L}}$ overexpressing cells were established. Overexpression of c-FLIP ${ }_{L}$ attenuated apoptosis (Fig. 4C) and PARP cleavage (Fig. 4D) induced by metformin. Taken together, metformin-induced apoptosis was associated with the degradation of $\mathrm{c}-\mathrm{FLIP}_{\mathrm{L}}$ through activation of caspase-8. ROS is not involved in metformin-mediated apoptosis in A498 cells. ROS is an important regulator of apoptosis (26). A previous report demonstrated that metformin induces ROS production in breast cancer cells (23). Therefore, the capacity of metformin to induce ROS production in A498 human renal carcinoma cells was investigated using flow cytometry. As demonstrated in Fig. 5A, metformin treatment increased ROS production $1 \mathrm{~h}$ post-treatment, and pretreatment with the anti-oxidant N-acetyl-L-cysteine (NAC, a ROS scavenger) inhibited metformin-induced ROS production. To confirm whether ROS generation served a key role in metformin-mediated apoptosis, A498 cells were pretreated with NAC for $30 \mathrm{~min}$. Pretreatment with NAC did not inhibit metformin-induced morphological changes and apoptosis in A498 cells (Fig. 5B and C). Furthermore, NAC did not 

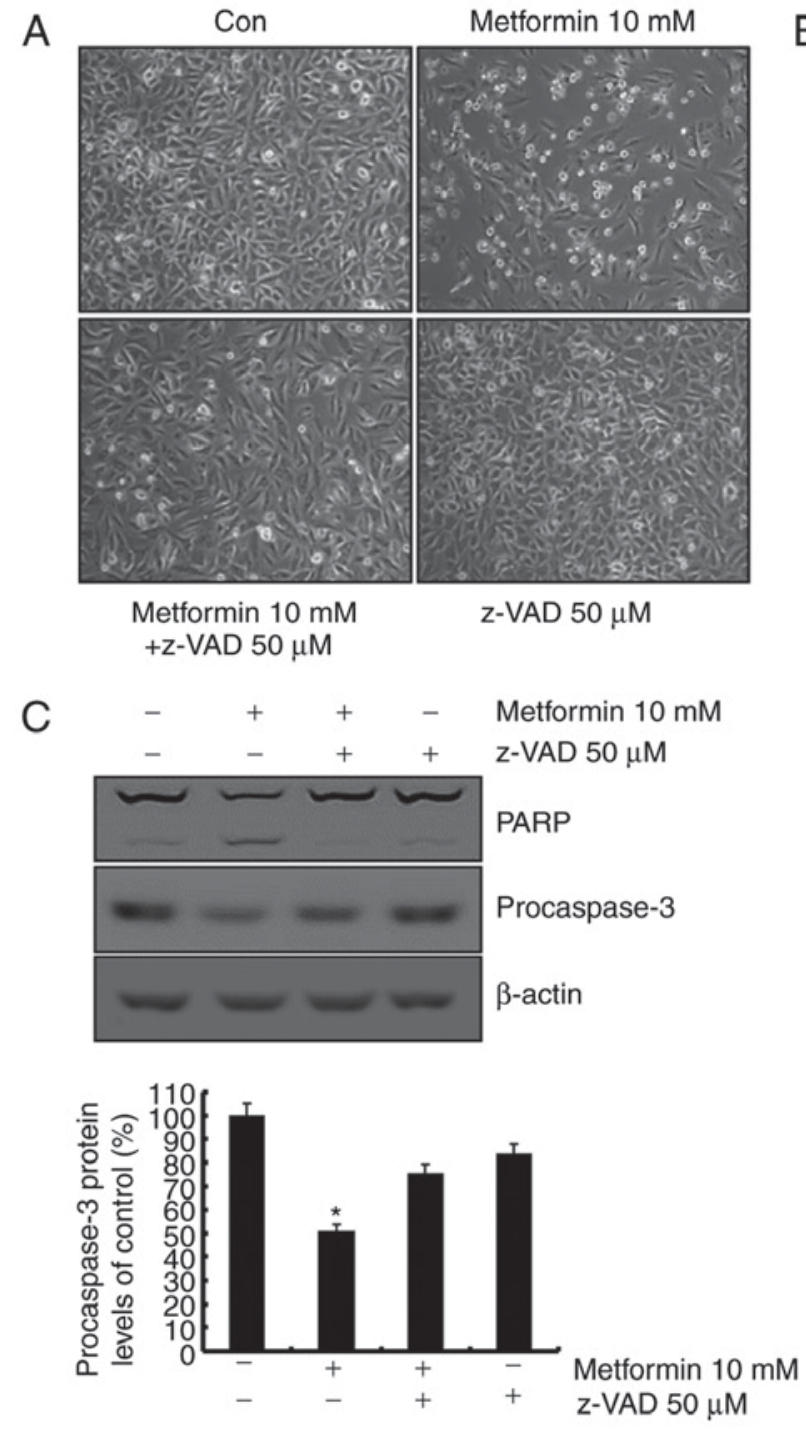
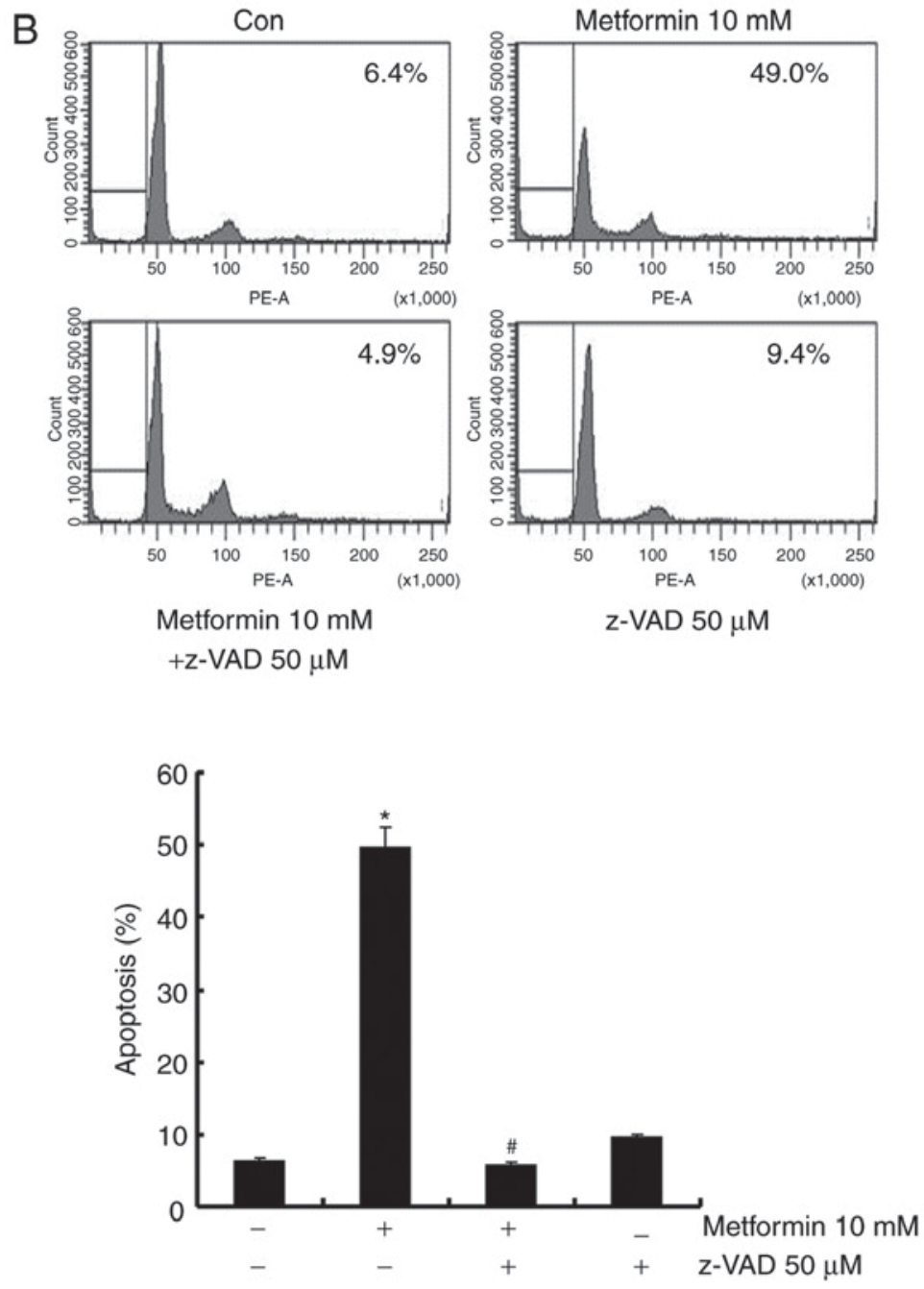

Figure 3. Metformin induces apoptosis by a caspase-dependent signaling pathway in A498 cells. (A) A498 cells were pretreated with $50 \mu \mathrm{M}$ z-VAD-fmk or a solvent for $30 \mathrm{~min}$ and incubated with $10 \mathrm{mM}$ metformin for $24 \mathrm{~h}$. Morphological features were analyzed using light microscopy at x 200 magnification. (B) A498 cells were cultured with $50 \mu \mathrm{M}$ z-VAD-fmk or the vehicle for 30 min prior to treatment with metformin (10 mM) for 24 h. The sub-G1 fraction was determined using flow cytometry. Representative FACS histograms are presented in the upper panel, cumulative data are presented in the lower panel. (C) A498 cells were incubated with $10 \mathrm{mM}$ metformin for $24 \mathrm{~h}$ in the presence or absence of $50 \mu \mathrm{M}$ z-VAD-fmk. PARP, procaspase-3 and $\beta$-actin expression was analyzed using western blotting. $\beta$-actin was used as the loading control. Band density of procaspase-3 was analyzed using Image J software. All data are expressed as the mean \pm standard deviation of three independent experiments. ${ }^{*} \mathrm{P}<0.05$ compared with untreated cells, ${ }^{\#} \mathrm{P}<0.05$ compared with metformin-treated cells. z-VAD-fmk, benzyloxycarbonyl-Val-Ala-Asp-fluorometyhlketone; PARP, poly(ADP-ribose) polymerase.

prevent PARP cleavage, caspase activation and degradation of c-FLIP $\mathrm{L}_{\mathrm{L}}$ protein in metformin-treated cells (Fig. 5D). These results suggested that ROS generation was not critical for the induction of apoptosis by metformin.

\section{Discussion}

Metformin has been used as a therapeutic agent for diabetic patients (27). It was reported to possess various effects, including anti-proliferation, anti-inflammation, anti-angiogenesis and anti-invasion (12,28-30). Metformin also has anti-apoptotic effects on prostate, hepatocellular carcinoma, gall bladder and breast cancer cell lines (31-34). In addition, the insulin receptor may serve a major role in facilitating cancer development via increases in insulin levels $(35,36)$. However, the specific apoptotic mechanism of action of metformin in human renal cancer cells has not been reported. The present study investigated whether metformin had an anti-cancer effect on human renal cell carcinoma A498 cells. It was revealed that metformin-mediated apoptosis led to the activation of caspase- 8 through the downregulation of c-FLIP protein expression level in A498 cells.

Apoptosis is the process of programmed cell death that is closely associated with caspase activation. Caspases can be divided into two main groups, namely initiator caspases (caspase-2, -8, -9 and -10) and executioner caspases (caspase-3, -6 and -7) (37). Caspase-8 enhances apoptosis through caspase- 3 activation. Caspase- 3 is a primary caspase because it is associated with the intrinsic and extrinsic signaling pathways of apoptosis (38). In the present study, the involvement of caspases in metformin-mediated apoptosis was examined. Caspase- 8 was activated by metformin, 
A
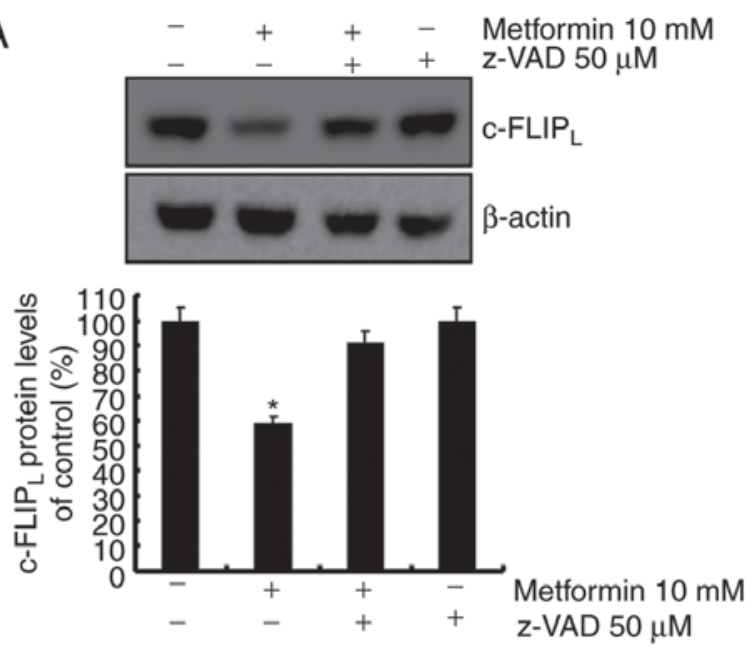

B

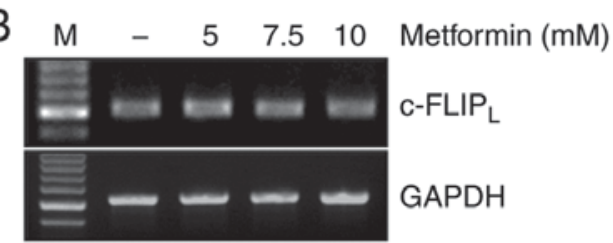

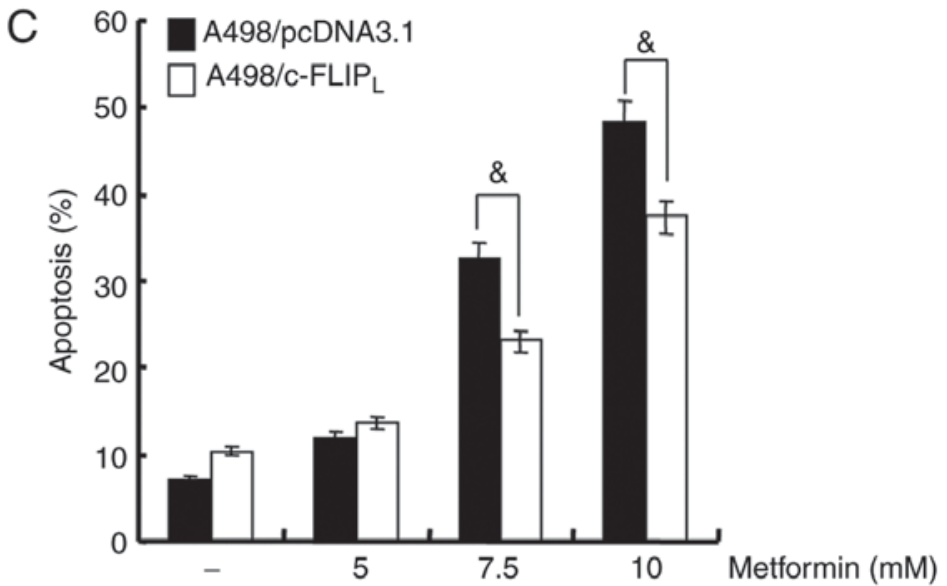

D

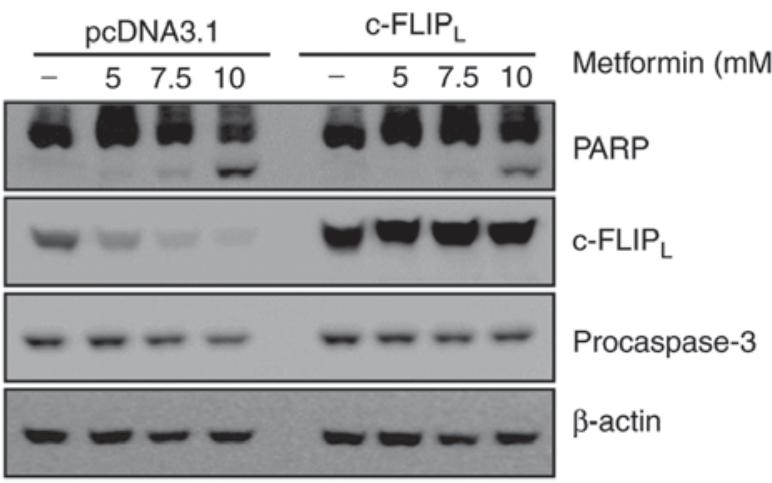

Figure 4. Degradation of c-FLIP $\mathrm{L}_{\mathrm{L}}$ protein is regulated via a caspase-dependent signaling pathway. (A) A498 cells were treated with $10 \mathrm{mM}$ metformin for $24 \mathrm{~h}$ in the presence or absence of $50 \mathrm{mM} \mathrm{z-VAD-fmk}$. c-FLIP $\mathrm{L}_{\mathrm{L}}$ and $\beta$-actin expression was analyzed using western blotting. $\beta$-actin was used as the loading control. Band density of the c-FLIPL protein was determined using the ImageJ program. (B) A498 cells were incubated with the indicated concentrations of metformin for 24 h. c-FLIP $\mathrm{L}_{\mathrm{L}}$ mRNA level was determined using reverse transcription-polymerase chain reaction. (C) A498 cells transfected with pcDNA3.1 or c-FLIP $\mathrm{L}_{\mathrm{L}}$ plasmid were treated for $24 \mathrm{~h}$ with different concentrations of metformin. The sub-G1 cell population was analyzed using flow cytometry. (D) The pcDNA3.1 and $\mathrm{c}-\mathrm{FLIP}_{\mathrm{L}}$ transfected cells were treated with varying concentrations of metformin. PARP, procaspase-3 and c-FLIP $\mathrm{L}_{\mathrm{L}}$ expression levels were determined using western blotting. $\beta$-actin was used as the loading control. All data are expressed as the mean \pm standard deviation of three independent experiments. ${ }^{*} \mathrm{P}<0.05$ compared with untreated cells, ${ }^{\&} \mathrm{P}<0.05$ compared with metformin-treated pcDNA3.1 cells. z-VAD-fmk, benzyloxycarbonyl-Val-Ala-Asp-fluoro-me thyl ketone; c-FLIP, cellular FLICE (FADD-like IL-1 $\beta$-converting enzyme)-inhibitory protein; PARP, poly(ADP-ribose) polymerase.

resulting in the emergence of $\mathrm{p} 43 / 41 \mathrm{kDa}$ fragments (Fig. 2A). Activation of the executioner caspase, caspase-3, was increased via metformin-induced apoptosis (Fig. 1C). In addition, z-VAD-fmk (a pan-caspase inhibitor) completely blocked metformin-induced apoptosis (Fig. 3). These results suggested that metformin-induced apoptosis was associated with caspase activation. Activation of the caspase cascade is modulated via upregulation of pro-apoptotic proteins and/or downregulation of anti-apoptotic proteins (39). In addition, activation of caspase- 8 at DISC is blocked via c-FLIP, which inhibits the death receptor-mediated apoptotic pathways (40). In the present study, metformin also decreased c-FLIP protein level in A498 cells in a dose-dependent manner (Fig. 2B). However, treatment with metformin did not affect c-FLIP ${ }_{\mathrm{L}}$ mRNA levels (Fig. 4B) and proteasomal degradation (data not shown). Previous reports also indicated that metformin had no effect on $\mathrm{c}-\mathrm{FLIP}_{\mathrm{L}}$ mRNA level and the proteasomal pathway in non-muscle invasive bladder cancer (NMIBC) (22). It was also revealed that c-FLIP ${ }_{L}$-overexpressing cells partly prevented metformin-induced apoptosis in A498 cells (Fig. 4). These results suggested that metformin-induced apoptosis occurred via degradation of $\mathrm{c}-\mathrm{FLIP}_{\mathrm{L}}$ protein. Metformin has also been reported to suppress the expression levels of anti-apoptotic proteins, including Bcl-2, Bcl-XL, Mcl-1, c-IAP2 and XIAP in primary ovarian cell lines, p53-deficient cells, colorectal and breast cancer cell lines, respectively (41-44). It was demonstrated that Bcl-2, Bcl-XL, Mcl-1, c-IAP2 and XIAP did not affect metformin-treated A498 cells (Fig. 2B). These results demonstrated that suppression of the anti-apoptotic protein, c-FLIP ${ }_{\mathrm{L}}$, was associated with metformin-induced apoptosis in A498 cells.

Reactive oxygen species (ROS) are important mediators of apoptosis in several cancer cell lines (45-48). Previous reports demonstrated that metformin modulated apoptosis through ROS production in hepatoma, ovary and breast cancer cell lines $(49,50)$. Therefore, the association between metformin-mediated apoptosis and ROS generation was investigated. In the present study, metformin was observed to stimulate ROS generation in A498 cells. Pretreatment with $\mathrm{N}$-acetylcysteine did not prevent metformin-induced apoptosis (Fig. 5). These results suggested that metformin-induced ROS generation was not associated with metformin-mediated apoptosis in A498 cells. 


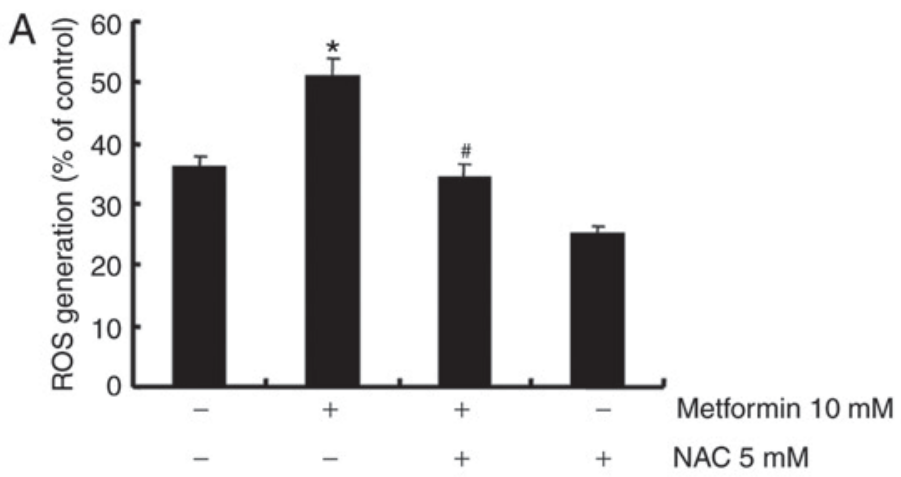

B
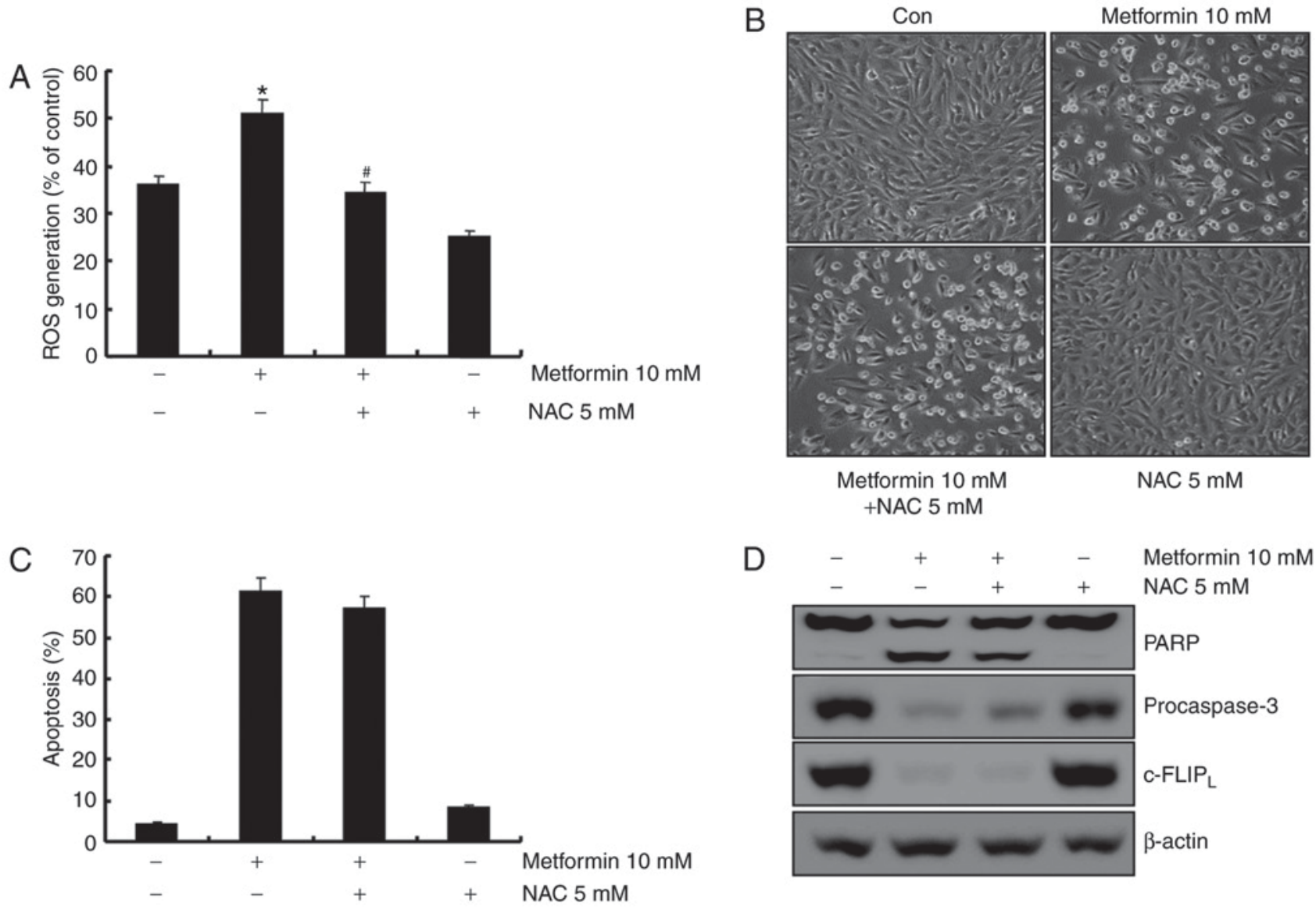

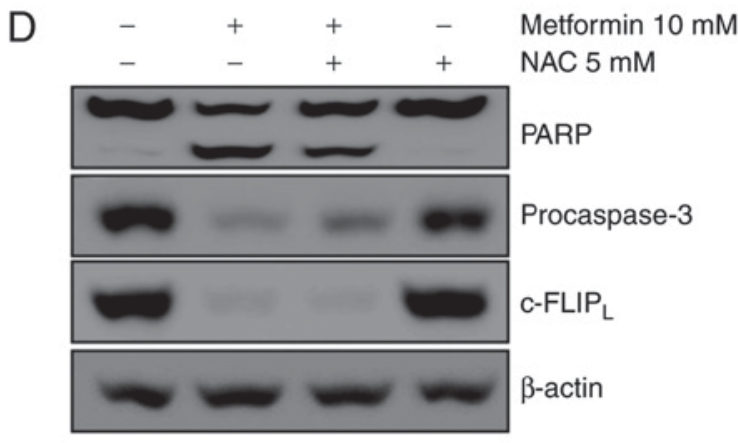

Figure 5. Metformin-mediated apoptosis in A498 cells was not affected by reactive oxygen species generation. (A) Cells were pretreated with 5 mM NAC for 30 min and incubated with $10 \mathrm{mM}$ metformin for $1 \mathrm{~h}$. $\mathrm{H}_{2}$ DCFDA fluorescence was quantified with flow cytometry. (B) A498 cells were incubated with $5 \mathrm{mM}$ NAC or the vehicle for $30 \mathrm{~min}$ prior to treatment with $10 \mathrm{mM}$ metformin for $24 \mathrm{~h}$. Morphological changes were analyzed using a light microscope at x 200 magnification. (C) A498 cells were pretreated with $5 \mathrm{mM} \mathrm{NAC}$ or the solvent for $30 \mathrm{~min}$ and incubated in the presence or absence of $10 \mathrm{mM}$ metformin for $24 \mathrm{~h}$. The sub-G1 cell fraction was analyzed using flow cytometry. (D) A498 cells were pretreated with $5 \mathrm{mM}$ NAC or the solvent for 30 min and incubated with $10 \mathrm{mM}$ metformin for $24 \mathrm{~h}$. PARP, procaspase-3, c-FLIP $\mathrm{L}_{\mathrm{L}}$ and $\beta$-actin expression levels were analyzed using western blotting. $\beta$-actin was used as the loading control. All data are expressed as the mean \pm standard deviation of three independent experiments. ${ }^{*} \mathrm{P}<0.05$ compared with untreated cells, ${ }^{,} \mathrm{P}<0.05$ compared with metformin-treated cells. NAC, N-acetyl-L-cysteine; PARP, poly(ADP-ribose) polymerase; c-FLIP, cellular FLICE (FADD-like IL-1 $\beta$-converting enzyme)-inhibitory protein; ROS, reactive oxygen species.

Taken together, these results demonstrated that metformin-induced apoptosis was mediated by the degradation of c-FLIP ${ }_{\mathrm{L}}$ protein via activation of caspase-8 in A498 human renal cell carcinoma cells. This suggested that metformin can serve the role of a chemotherapeutic agent for diabetes, as well as an anti-cancer agent.

\section{Acknowledgements}

Not applicable.

\section{Funding}

The present study was supported by the Basic Science Research Program through the National Research Foundation of Korea (NRF) funded by the Ministry of Education (grant no. 2017R1D1A1B3030961).

\section{Availability of data and materials}

All data generated or analyzed during present study are included within the article.

\section{Authors' contributions}

JJ and JK designed the study, collected and analyzed the data. TL, IS and ES advised on the morphological images and performed the data analysis. JJ and JK drafted and wrote the manuscript. TL and JK revised the manuscript critically for intellectual content. All authors gave intellectual input to the study and approved the final version of the manuscript.

\section{Ethics approval and consent to participate}

This research was approved by the Ethics Committee of Yeungnam University (Daegu, South Korea). All procedures were performed according to the ethical standards of Ethics Committee of Yeungnam University and with the 1964 Helsinki declaration and its later amendments or comparable ethical standards.

\section{Consent for publication}

Not applicable. 


\section{Competing interests}

The authors declare that they have no competing interests.

\section{References}

1. Low G, Huang G, Fu W, Moloo Z and Girgis S: Review of renal cell carcinoma and its common subtypes in radiology. World J Radiol 8: 484-500, 2016.

2. Atzpodien J, Kirchner H and Poliwoda H: Interleukin 2 based ambulatory therapy of metastatic renal cell carcinoma. Med Klin (Munich) 91 (Suppl 3): S38-S43, 1996 (In German).

3. Rabinovitch RA, Zelefsky MJ, Gaynor JJ and Fuks Z: Patterns of failure following surgical resection of renal cell carcinoma: Implications for adjuvant local and systemic therapy. J Clin Oncol 12: 206-212, 1994

4. Malek M, Aghili R, Emami Z and Khamseh ME: Risk of cancer in diabetes: The effect of metformin. ISRN Endocrinol 2013: 636927, 2013.

5. Algire C, Amrein L, Zakikhani M, Panasci L and Pollak M: Metformin blocks the stimulative effect of a high-energy diet on colon carcinoma growth in vivo and is associated with reduced expression of fatty acid synthase. Endocr Relat Cancer 17: 351-360, 2010

6. Zhang ZJ, Zheng ZJ, Kan H, Song Y, Cui W, Zhao G and Kip KE: Reduced risk of colorectal cancer with metformin therapy in patients with type 2 diabetes: A meta-analysis. Diabetes Care 34 2323-2328, 2011

7. Nair V, Pathi S, Jutooru I, Sreevalsan S, Basha R, Abdelrahim M, Samudio I and Safe S: Metformin inhibits pancreatic cancer cell and tumor growth and downregulates Sp transcription factors. Carcinogenesis 34: 2870-2879, 2013.

8. Gotlieb WH, Saumet J, Beauchamp MC, Gu J, Lau S, Pollak MN and Bruchim I: In vitro metformin anti-neoplastic activity in epithelial ovarian cancer. Gynecol Oncol 110 246-250, 2008.

9. Emami Riedmaier A, Fisel P, Nies AT, Schaeffeler E and Schwab M: Metformin and cancer: From the old medicine cabinet to pharmacological pitfalls and prospects. Trends Pharmacol Sci 34: 126-135, 2013

10. Zhang ZJ, Zheng ZJ, Shi R, Su Q, Jiang Q and Kip KE: Metformin for liver cancer prevention in patients with type 2 diabetes: A systematic review and meta-analysis. J Clin Endocrinol Metab 97: 2347-2353, 2012

11. Rice S, Pellat L, Ahmetaga A, Bano G, Mason HD and Whitehead SA: Dual effect of metformin on growth inhibition and oestradiol production in breast cancer cells. Int $\mathrm{J}$ Mol Med 35: 1088-1094, 2015.

12. Fang Z, Xu X, Zhou Z, Xu Z and Liu Z: Effect of metformin on apoptosis, cell cycle arrest migration and invasion of A498 cells. Mol Med Rep 9: 2251-2256, 2014.

13. Ucbek A, Ozunal ZG, Uzun O and Gepdiremen A: Effect of metformin on the human T98G glioblastoma multiforme cell line. Exp Ther Med 7: 1285-1290, 2014.

14. Jung TW, Lee MW, Lee YJ and Kim SM: Metformin prevents endoplasmic reticulum stress-induced apoptosis through AMPK-PI3K-c-Jun NH2 pathway. Biochem Biophys Res Commun 417: 147-152, 2012.

15. Fujimori T, Kato K, Fujihara S, Iwama H, Yamashita $T$, Kobayashi K, Kamada H, Morishita A, Kobara H, Mori H, et al: Antitumor effect of metformin on cholangiocarcinoma: In vitro and in vivo studies. Oncol Rep 34: 2987-2996, 2015

16. He MX and He YW: A role for c-FLIP(L) in the regulation of apoptosis, autophagy, and necroptosis in T lymphocytes. Cell Death Differ 20: 188-197, 2013.

17. Bagnoli M,Ambrogi F, PilottiS,Alberti P,Ditto A,BarbareschiM, Galligioni E, Biganzoli E, Canevari S and Mezzanzanica D: c-FLIPL expression defines two ovarian cancer patient subsets and is a prognostic factor of adverse outcome. Endocr Relat Cancer 16: 443-453, 2009.

18. Safa AR, Day TW and Wu CH: Cellular FLICE-like inhibitory protein (C-FLIP): A novel target for cancer therapy. Current Cancer Drug Targets 8: 37-46, 2008.

19. Bagnoli M, Canevari S and Mezzanzanica D: Cellular FLICE-inhibitory protein (c-FLIP) signalling: A key regulator of receptor-mediated apoptosis in physiologic context and in cancer. Int J Biochem Cell Biol 42: 210-213, 2010.
20. Koenig A, Buskiewicz IA, Fortner KA, Russell JQ, Asaoka T, He YW, Hakem R, Eriksson JE and Budd RC: The c-FLIPL cleavage product $\mathrm{p} 43$ FLIP promotes activation of extracellular signal-regulated kinase (ERK), nuclear factor kappaB (NF-кB), and caspase-8 and T cell survival. J Biol Chem 289: 1183-1191, 2014.

21. Nazim UM, Moon JH, Lee JH, Lee YJ, Seol JW, Eo SK, Lee JH and Park SY: Activation of autophagy flux by metformin downregulates cellular FLICE-like inhibitory protein and enhances TRAIL-induced apoptosis. Oncotarget 7: 23468-23481, 2016.

22. Zhang T, Wang X, He D, Jin X and Guo P: Metformin sensitizes human bladder cancer cells to TRAIL-induced apoptosis through mTOR/S6K1-mediated downregulation of c-FLIP. Anticancer Drugs 25: 887-897, 2014.

23. Gao ZY, Liu Z, Bi MH, Zhang JJ, Han ZQ, Han X, Wang HY, Sun GP and Liu H: Metformin induces apoptosis via a mitochondria-mediated pathway in human breast cancer cells in vitro. Exp Ther Med 11: 1700-1706, 2016.

24. Riedl SJ and Shi Y: Molecular mechanisms of caspase regulation during apoptosis. Nat Rev Mol Cell Biol 5: 897-907, 2004.

25. Ili CG, Brebi P, Tapia O, Sandoval A, Lopez J, Garcia P, Leal P, Sidransky D, Guerrero-Preston R and Roa JC: Cellular FLICE-like inhibitory protein long form (c-FLIPL) overexpression is related to cervical cancer progression. Int J Gynecol Pathol 32: 316-322, 2013.

26. Ding H, Han C, Guo D, Chin YW, Ding Y, Kinghorn AD and D'Ambrosio SM: Selective induction of apoptosis of human oral cancer cell lines by avocado extracts via a ROS-mediated mechanism. Nutr Cancer 61: 348-356, 2009.

27. Maruthur NM, Tseng E, Hutfless S, Wilson LM, Suarez-Cuervo C, Berger Z, Chu Y, Iyoha E, Segal JB and Bolen S: Diabetes medications as monotherapy or metformin-based combination therapy for type 2 diabetes: A systematic review and Meta-analysis. Ann Intern Med 164: 740-751, 2016.

28. Xu HY, Fang W, Huang ZW, Lu JC, Wang YQ, Tang QL, Song GH, Kang Y, Zhu XJ, Zou CY, et al: Metformin reduces SATB2-mediated osteosarcoma stem cell-like phenotype and tumor growth via inhibition of N-cadherin/NF- $\mathrm{kB}$ signaling. Eur Rev Med Pharmacol Sci 21: 4516-4528, 2017.

29. Figueroa-González G, Garcia-Castillo V, Coronel-Hernández J, López-Urrutia E, León-Cabrera S, Arias-Romero LE, Terrazas LI, Rodríguez-Sosa M, Campos-Parra AD, Zúñiga-Calzada E, et al: Anti-inflammatory and antitumor activity of a triple therapy for a colitis-related colorectal cancer. J Cancer 7: 1632-1644, 2016.

30. Yang Y, Jin G, Liu H, Liu K, Zhao J, Chen X, Wang D, Bai R, $\mathrm{Li}$ X, Jang Y, et al: Metformin inhibits esophageal squamous cell carcinoma-induced angiogenesis by suppressing JAK/STAT3 signaling pathway. Oncotarget 8: 74673-74687, 2017.

31. Tran LNK, Kichenadasse G, Butler LM, Centenera MM, Morel KL, Ormsby RJ, Michael MZ, Lower KM and Sykes PJ: The combination of metformin and valproic acid induces synergistic apoptosis in the presence of p53 and androgen signaling in prostate cancer. Mol Cancer Ther 16: 2689-2700, 2017.

32. Tsai HH, Lai HY, Chen YC, Li CF, Huang HS, Liu HS, Tsai YS and Wang JM: Metformin promotes apoptosis in hepatocellular carcinoma through the CEBPD-induced autophagy pathway. Oncotarget 8: 13832-13845, 2017.

33. Bi T, Zhu A, Yang X, Qiao H, Tang J, Liu Y and Lv R: Metformin synergistically enhances antitumor activity of cisplatin in gallbladder cancer via the PI3K/AKT/ERK pathway. Cytotechnology 70: 439-448, 2018.

34. Al-Zaidan L, El Ruz RA and Malki AM: Screening novel molecular targets of metformin in breast cancer by proteomic approach. Front Public Health 5: 277, 2017.

35. Belfiore A and Malaguarnera R: Insulin receptor and cancer. Endocr Relat Cancer 18: R125-R147, 2011.

36. Rizos CV and Elisaf MS: Metformin and cancer. Eur J Pharmacol 705: 96-108, 2013

37. Galluzzi L, Lopez-Soto A, Kumar S and Kroemer G: Caspases connect cell-death signaling to organismal homeostasis. Immunity 44: 221-231, 2016.

38. Walters J, Pop C, Scott FL, Drag M, Swartz P, Mattos C, Salvesen GS and Clark AC: A constitutively active and uninhibitable caspase-3 zymogen efficiently induces apoptosis. Biochem J 424: 335-345, 2009.

39. Spagnuolo C, Cerella C, Russo M, Chateauvieux S, Diederich M and Russo GL: Quercetin downregulates Mcl-1 by acting on mRNA stability and protein degradation. Br J Cancer 105: 221-230, 2011.

40. Kruidering $M$ and Evan GI: Caspase- 8 in apoptosis: The beginning of 'the end'? IUBMB Life 50: 85-90, 2000 
41. Patel S, Singh N and Kumar L: Evaluation of effects of metformin in primary ovarian cancer cells. Asian Pac J Cancer Prev 16: 6973-6979, 2015.

42. Li X, Li B, Ni Z, Zhou P, Wang B, He J, Xiong H, Yang F, Wu Y, Lyu X, et al: Metformin synergizes with BCL-XL/BCL-2 inhibitor ABT-263 to induce apoptosis specifically in p53defective cancer cells. Mol Cancer Ther 16: 1806-1818, 2017.

43. Park SH, Lee DH, Kim JL, Kim BR, Na YJ, Jo MJ, Jeong YA Lee SY, Lee SI, Lee YY and Oh SC: Metformin enhances TRAIL-induced apoptosis by Mcl-1 degradation via Mule in colorectal cancer cells. Oncotarget 7: 59503-59518, 2016.

44. Strekalova E, Malin D, Rajanala H and Cryns VL: Metformin sensitizes triple-negative breast cancer to proapoptotic TRAIL receptor agonists by suppressing XIAP expression. Breast Cancer Res Treat 163: 435-447, 2017.

45. Jang JH, Iqbal T, Min KJ, Kim S, Park JW, Son EI, Lee TJ and Kwon TK: Helenalin-induced apoptosis is dependent on production of reactive oxygen species and independent of induction of endoplasmic reticulum stress in renal cell carcinoma. Toxicol In Vitro 27: 588-596, 2013

46. Woo SM, Min KJ and Kwon TK: Calyculin A causes sensitization to tumor necrosis factor-related apoptosis-inducing ligand (TRAIL)-induced apoptosis by ROS-mediated down-regulation of cellular FLICE-inhibiting protein (c-FLIP) and by enhancing death receptor 4 mRNA stabilization. Apoptosis 17: 1223-1234, 2012.
47. Wang Y, Yu X, Song H, Feng D, Jiang Y, Wu S and Geng J: The STAT-ROS cycle extends IFN-induced cancer cell apoptosis. Int J Oncol 52: 305-313, 2018.

48. Sheikh BY, Sarker MMR, Kamarudin MNA and Mohan G: Antiproliferative and apoptosis inducing effects of citral via p53 and ROS-induced mitochondrial-mediated apoptosis in human colorectal HCT116 and HT29 cell lines. Biomed Pharmacother 96: 834-846, 2017.

49. Rogalska A, Bukowska B and Marczak A: Metformin and epothilone A treatment up regulate pro-apoptotic PARP-1, Casp-3 and $\mathrm{H} 2 \mathrm{AX}$ genes and decrease of AKT kinase level to control cell death of human hepatocellular carcinoma and ovary adenocarcinoma cells. Toxicol In Vitro 47: 48-62, 2018.

50. Haugrud AB, Zhuang Y, Coppock JD and Miskimins WK: Dichloroacetate enhances apoptotic cell death via oxidative damage and attenuates lactate production in metformin-treated breast cancer cells. Breast Cancer Res Treat 147: 539-550, 2014. 